\title{
\& Research Square \\ Experimental reef communities persist under future ocean acidification and warming
}

Christopher Jury ( $\sim$ jurycp@hawaii.edu )

University of Hawai'i at Manoa

Keisha Bahr

Texas A\&M University-Corpus Christi

\section{Evan Barba}

Hawai'i Institute of Marine Biology, School of Ocean and Earth Science and Technology, University of Hawai'i at Mānoa

\section{Russell Brainard}

Red Sea Research Center, King Abdullah University of Science and Technology

\section{Annick Cros}

Woods Hole Oceanographic Institution

\section{Kerri Dobson}

School of Earth Sciences, The Ohio State University

\section{Andrew Graham}

Hawai'i Institute of Marine Biology, School of Ocean and Earth Science and Technology, University of Hawai'i at Mānoa

\section{Rowan McLachlan}

School of Earth Sciences, The Ohio State University

\section{Craig Nelson}

Daniel K. Inouye Center for Microbial Oceanography: Research and Education, Department of Oceanography and Sea Grant College Program, School of Ocean and Earth Science and Technology, University of https://orcid.org/0000-0003-2525-3496

\section{James Price}

School of Earth Sciences, The Ohio State University

\section{Mariana Rocha de Souza}

Hawai'i Institute of Marine Biology, School of Ocean and Earth Science and Technology, University of Hawai'i at Mānoa

\section{Leah Shizuru}

Hawai'i Institute of Marine Biology, School of Ocean and Earth Science and Technology, University of Hawai'i at Mānoa

\section{Celia Smith}

School of Life Sciences, College of Natural Sciences, University of Hawai'i at Mānoa 
Daniel K. Inouye Center for Microbial Oceanography: Research and Education, Department of Oceanography and Sea Grant College Program, School of Ocean and Earth Science and Technology, University of

\section{Cheryl Squair}

School of Life Sciences, College of Natural Sciences, University of Hawai'i at Mānoa

\section{Molly Timmers}

Pacific Islands Fisheries Science Center, National Oceanic and Atmospheric Administration

\section{Tiana Tran}

School of Ocean and Earth Science and Technology, University of Hawai囚i at Mānoa

\section{Jan Vicente}

Hawai'i Institute of Marine Biology, School of Ocean and Earth Science and Technology, University of Hawai'i at Mānoa

\section{Maryann Webb}

Hawai'i Institute of Marine Biology, School of Ocean and Earth Science and Technology, University of Hawai'i at Mānoa

\section{Nicole Yamase}

Marine Biology Graduate Program, College of Natural Sciences and School of Ocean and Earth Science and Technology, University of Hawai囚i at Mānoa

\section{Andrea Grottoli}

The Ohio State University https://orcid.org/0000-0001-6053-9452

\section{Robert Toonen}

Hawai'i Institute of Marine Biology, School of Ocean and Earth Science and Technology, University of Hawai'i at Mānoa

\section{Article}

Keywords: coral reefs, mesocosm coral reef communities, ocean acidification and warming

Posted Date: August 27th, 2021

DOl: https://doi.org/10.21203/rs.3.rs-640089/v1

License: (a) (1) This work is licensed under a Creative Commons Attribution 4.0 International License. Read Full License 


\section{Abstract}

Coral reefs are among the most sensitive ecosystems affected by ocean acidification and warming, and are predicted to shift from net accreting calcifier-dominated systems to net eroding algal-dominated systems over the coming decades. Here we present a long-term experimental study examining the responses of entire mesocosm coral reef communities to acidification $\left(-0.2 \mathrm{pH}\right.$ units), warming $\left(+2^{\circ} \mathrm{C}\right)$, and combined future ocean $\left(-0.2 \mathrm{pH},+2^{\circ} \mathrm{C}\right)$ treatments. We show that under future ocean conditions, net calcification rates declined yet remained positive, corals showed reduced abundance yet were not extirpated, and community composition shifted while species richness was maintained. Our results suggest that under Paris Climate Agreement targets, coral reefs could persist in an altered functional state rather than collapse.

\section{Main Text}

Many studies project that the combination of ocean acidification and warming will lead to the functional collapse of coral reef ecosystems at a global scale over the next few decades, driving major losses in biodiversity and ecosystem services ${ }^{1-5}$. Reefs are expected to shift from net calcification to net carbonate dissolution sometime later this century when atmospheric $\mathrm{CO}_{2}$ reaches $550-650 \mu \mathrm{atm}$, seawater $\mathrm{pH}$ declines by $0.1-0.15$ units, and seawater temperature increases by $1-1.5^{\circ} \mathrm{C}^{4,6}$. Likewise, corals are expected to be essentially extirpated from reefs in the next few decades ( $>99 \%$ decline $)^{7,8}$ once coral bleaching becomes an annual phenomenon. These projected future scenarios are typically based on either short-term laboratory perturbation experiments with few species that are then scaled up to longterm responses of complex communities in nature $3,4,9,10$ or in situ observations of coral reefs that span natural gradients in chemistry or thermal stress ${ }^{11-14}$. Laboratory experiments, however, typically do not include natural ecological interactions among species which could affect community function, and some experiments may not have provided organisms with sufficient time to fully respond to the treatments. Likewise, natural gradient studies do not reflect the intensity of heat stress expected later this century and often do not incorporate acidification and warming simultaneously (but see ${ }^{15-17}$ ). An alternative approach to lab or natural gradient studies is the use of mesocosms which allow diverse communities to be exposed to future ocean levels of acidification and warming at the same time while preserving realistic ecological interactions and environmental conditions ${ }^{18-23}$. While no study can incorporate every aspect of future reef ecosystem composition and function, mesocosms provide some of the most complete experimental systems to test the hypothesis that sustained future ocean acidification and warming will induce the functional collapse of experimental reef communities. With eight coral species representing three divergent families (Acroporidae, Pocilloporidae, and Poritidae), both major evolutionary lineages of scleractinians (Complexa and Robusta), and all four of their major life history strategies (see Supplementary Information), along with the literally thousands of other species surveyed in our study (ranging from bacteria and archaea to many of the major animal and algal phyla), we present a long-term experimental examination of coral reef organismal and community responses under future ocean 
conditions. This dataset provides unprecedented insights into the likely responses of coral reef communities to ocean acidification and warming over coming years.

We conducted a two-year ecologically realistic outdoor flow-through mesocosm experiment at the Hawai邓i Institute of Marine Biology to examine the long-term responses of biologically diverse coral reef communities to chronic acidification and warming similar to levels projected to occur toward the end of this century given current commitments under the Paris Climate Agreement (conditions between Representative Concentration Pathways RCP 6.0 and RCP 8.5) ${ }^{24}$. Mesocosms were initially stocked with replicate communities of the regionally most common reef-building corals, each sourced from multiple locations around the island of O'ahu, as well as reef rubble, reef sand, algae, invertebrates, and fish (see Supplementary Information). We determined the multilocus genotype of each coral colony sampled to ensure results were not biased by inclusion of clones. Replicate clonal fragments (ramets) of each genetically unique coral colony (genet) were included in all four treatments. Over time, the mesocosms recruited a diverse assemblage of algae, invertebrates, and microbes (Fig. 1). These communities developed under one of four treatments with 10 mesocosms per treatment: control treatment (present-day $\mathrm{pH}$ and temperature), ocean acidification treatment (present-day temperature with acidification of $-0.2 \mathrm{pH}$ units relative to control), ocean warming treatment (present-day $\mathrm{pH}$ with elevated temperature of $+2{ }^{\circ} \mathrm{C}$ relative to control), or combined future ocean treatment (both acidification of $-0.2 \mathrm{pH}$ units and elevated temperature of $+2{ }^{\circ} \mathrm{C}$ relative to control). All mesocosms experienced natural diurnal and seasonal variation in temperature, chemistry, and irradiance (Table 1, Fig. 2, S1). After approximately two years of exposure, we assessed (i) coral bleaching, survivorship, recruitment, skeletal extension, metabolism, and energy reserves, (ii) net calcification by the mesocosm communities, coral communities, and rubbleassociated communities, and (iii) community structure and species richness of the major functional groups, including benthic algae and invertebrates, coral-associated algal endosymbionts (Symbiodiniaceae), coral-associated microbes, and water column-associated microbes (Fig. S2).

Table 1. Carbonate chemistry and temperature from the experiment. Data are daily mean values derived from weekly sampling at $1200 \mathrm{hr}$ as well as monthly sampling every $4 \mathrm{hr}$ over the diel cycle (see Supplementary Information) and are shown as mean \pm SD. The uncertainties associated with these values reflect daily and seasonal variability, as well as variability among replicate mesocosms in each treatment. The mean uncertainties among mesocosms on a given sampling day are provided in parentheses. Note that the variation among mesocosms is relatively small and most of the variation is explained by daily and seasonal fluctuation of these parameters. See Fig. 2, S1 for additional environmental information. 


\begin{tabular}{lllllll} 
Treatment & $\begin{array}{l}\text { Salinity } \\
(\mathbf{p s u})\end{array}$ & $\begin{array}{l}\text { Temperature } \\
\left({ }^{\circ} \mathrm{C}\right)\end{array}$ & $\mathbf{p H}$ & $\begin{array}{l}\text { Total } \\
\text { alkalinity } \\
\left(\mu \mathrm{mol}_{\mathbf{~ k g}}{ }^{-1}\right)\end{array}$ & $\begin{array}{l}\mathbf{p C O}_{2} \\
(\mu \mathrm{\mu tm})\end{array}$ & $\Omega_{\text {arag }}$ \\
\hline Control & $34.26 \pm 0.34$ & $25.08 \pm 1.18$ & $7.99 \pm 0.05$ & $2177 \pm 51$ & $448 \pm 60$ & $2.88 \pm 0.32$ \\
& $(0.02)$ & $(0.09)$ & $(0.01)$ & $(12)$ & $(12)$ & $(0.05)$ \\
\hline $\begin{array}{l}\text { Ocean } \\
\text { acidification }\end{array}$ & $34.26 \pm 0.34$ & $25.09 \pm 1.18$ & $7.78 \pm 0.07$ & $2184 \pm 49$ & $794 \pm 132$ & $1.94 \pm 0.31$ \\
& $(0.02)$ & $(0.09)$ & $(0.02)$ & $(12)$ & $(44)$ & $(0.08)$ \\
\hline Ocean warming & $34.29 \pm 0.34$ & $26.99 \pm 1.18$ & $7.98 \pm 0.05$ & $2187 \pm 49$ & $453 \pm 61$ & $3.06 \pm 0.33$ \\
& $(0.02)$ & $(0.17)$ & $(0.01)$ & $(12)$ & $(16)$ & $(0.07)$ \\
\hline Future ocean & $34.30 \pm 0.34$ & $27.03 \pm 1.15$ & $7.77 \pm 0.07$ & $2196 \pm 48$ & $811 \pm 134$ & $2.07 \pm 0.32$ \\
& $(0.02)$ & $(0.16)$ & $(0.02)$ & $(9)$ & $(45)$ & $(0.08)$
\end{tabular}

Corals in the treatments with elevated temperature (ocean warming and combined future ocean treatments) were exposed to severe ${ }^{3}$ heat stress in successive years. These corals experienced temperatures at or above the nominal bleaching threshold for 3.5 months per year, during which they accumulated 24 Degree Heating Weeks (DHW) annually (Fig. 2). Many studies predict that this level of repeated annual bleaching stress should have been more than sufficient to extirpate corals in our elevated temperature mesocosms ${ }^{1,3,7,8}$ and that acidification should have exacerbated the heat stress ${ }^{3}$. As expected, many of the corals that bleached severely subsequently died during the trials, with up to $13 \%$ of the corals in the heated treatments remaining pale or bleached at the end of the experiment, compared to less than $2 \%$ under the control and ocean acidification treatments (Fig. S3, Table S1). Contrary to projections of near total mortality 7,8 , coral survivorship was reduced by only $35 \%$ in the heated treatments compared to the present-day temperature treatments, with no evidence that acidification affected either survivorship or the incidence of bleaching (Fig. S3, Table S1). Among the survivors, the extent of paling, however, was $14-18 \%$ higher in the ocean acidification, ocean warming, and combined future ocean treatments relative to the control (Fig. S3, Table S2). Indeed, some individual corals in this study bleached and died, whereas others bleached annually yet survived to the end, and still others never bleached at all. These responses differed by coral genus. All individuals of both species of Pocillopora paled or bleached, though some survived, whereas responses within the other genera were more variable and some individuals within each of the three Montipora species and the three Porites species exhibited all of these response patterns. Coral species richness declined under warming, primarily due to the loss of one or both Pocillopora species from many of the heated mesocosms (Table S3). Some corals are capable of increasing zooplankton feeding rates to survive and recover from bleaching ${ }^{25}$. Although we used unfiltered sea water and fishes in the mesocosms were fed to simulate natural zooplankton import to the communities (see Supplementary Information), live zooplankton densities in the mesocosms were at the 
lower end of values typically reported for reefs (Fig. S4), making our results potentially conservative. Among the surviving corals, horizontal skeletal extension was reduced $22 \%$ in the heated mesocosms (ocean warming and combined future ocean treatments) relative to those under present-day temperatures (control and ocean acidification treatments), but was unaffected by acidification (Fig. S5, Table S3). In contrast, total organic carbon fluxes increased under warming (Table S3, Fig. S4). Coral photosynthesis, respiration, and energy reserves, however, did not differ significantly among those individuals that survived the treatments (Fig. S5, Table S3). While severe, this 35\% reduction in survivorship and $22 \%$ decline in skeletal extension among the survivors is far less than the $>99 \%$ loss of corals projected for reef $^{7,8}$. The discrepancy between our data and these projections may reflect some of the challenges associated with scaling up prior results. In particular, few projections quantitatively account for the substantial variation in bleaching tolerance we observed within and among species or the biotic interactions which could modulate these outcomes ${ }^{26}$.

Large numbers of one coral species (Pocillopora acuta) recruited into the mesocosms, undoubtedly due to spawning of the adult corals housed in them ${ }^{18,27}$, but recruitment rate was unaffected by any of the treatments ${ }^{27}$. Similarly, we observed widespread spawning of another coral species (Montipora capitata) across all four treatments (CPJ pers. obs. in June 2018), though it was infeasible to assess reproductive output or gamete quality at the time of release. Hence, many of the corals grew from the size of prereproductive juveniles to reproductive adults (and completed a substantial fraction of their life cycles) over the course of the experiment. If coral individuals that are resistant to bleaching or resilient to annual bleaching (like some of those in this study) proliferate in the future, then they could help to offset some of the negative effects of ocean warming on coral abundance predicted for coral reefs. Indeed, coral communities in Hawai'i already appear to be mounting adaptive responses to climate change with bleaching and mortality occurring at higher temperatures and after longer exposures than reported 50 years ago ${ }^{17,28}$.

The calcification rates measured in the control mesocosm communities were very similar to those measured on the nearby reefs ${ }^{29}$, indicating that the mesocosms adequately replicated the processes involved in community calcification. Net calcification of the mesocosm communities (sometimes referred to as net community calcification, NCC, or net ecosystem calcification, NEC, in other studies) declined in all treatments relative to the control, with the largest decline under the combined future ocean scenario (Fig. 3, Table S3). The $19-24 \%$ reduction in mesocosm calcification attributable to acidification is lower but roughly similar to the $30 \%$ reduction measured on an experimentally acidified reef flat ${ }^{30}$, further illustrating the efficacy of our approach to simulate the natural system. Nevertheless, all communities continued calcifying. Even under the combined future ocean treatment, reef community calcification was positive, albeit at only $56 \%$ the rate of control reef communities. At present-day rates of calcification, however, few reefs are expected to accrete fast enough to be able to keep up with sea level change and many future reefs may become submerged as the oceans rise ${ }^{31}$. Acidification does not by itself kill corals but rather tends to inhibit their skeletal growth by an average of $15-20 \%{ }^{10}$, which may compromise their competitive abilities in nature $11,12,15$. Acidification, however, had no effect on net coral community 
calcification or skeletal extension within this study (Fig. 3, Fig. S5, Table S3). While these results differ from many prior laboratory experiments, both ex situ and in situ studies have found that some corals can maintain normal calcification rates under lower $\mathrm{pH}^{12,13,17,32-34}$. Further, irradiance and water flow are both known to affect coral responses to acidification ${ }^{19}$. We conducted this experiment using natural sunlight (attenuated by shade cloth to ambient levels at mean collection depth of $2 \mathrm{~m}$ ), rapid unfiltered natural seawater turnover rate ( $1 \mathrm{hr})$, and additional water circulation provided by seawater pumps (10-15 $\mathrm{cm} \mathrm{s}^{-1}$ ) to replicate light and flow conditions on the natural reefs as closely as possible (Fig. 2), which may help to explain the observed insensitivity of coral calcification to low $\mathrm{pH}$ relative to many previous laboratory studies. In addition, corals may show threshold responses to acidification such that they are able to maintain calcification rates under a $0.2 \mathrm{pH}$ unit reduction yet experience reduced calcification rates at higher levels of acidification ${ }^{17,18,35}$. Unlike acidification, elevated temperature reduced coral community calcification and coral abundance by nearly half due to bleaching, mortality, and reduced skeletal extension among the survivors (Fig. 3, Table S3). In contrast, net calcification by rubbleassociated communities declined under ocean acidification conditions yet was insensitive to warming (Fig. 3, Table S3). These results suggest that the measured reductions in calcification for mesocosm communities $22,23,36$ and natural communities ${ }^{6,30,37}$ due to acidification are driven largely by processes occurring within the reef framework and soft sediments rather than by the corals themselves. The calcification budget of the mesocosms exceeded that explained by the corals and rubble, and this additional carbonate production was likely from the growth of coralline algae, coral recruits, and other organisms which formed thick, calcified crusts on the mesocosm walls (Fig. 1). Future reefs will undoubtedly experience a major decline in growth due to the loss of corals from heat stress, and reduced calcification by the reef framework under acidification. Nonetheless, our findings indicate that under mitigated $\mathrm{CO}_{2}$ emissions consistent with current commitments under the Paris Climate Agreement, reefs may be capable of maintaining positive carbonate balances and net calcification despite these climate change stressors.

Corals are ecosystem engineers, yet coral reef biodiversity is derived largely from the array of algae, invertebrates, and microbes which live within, among, and upon the reefs. Coral reefs occupy less than $0.2 \%$ of the seafloor but are home to an estimated $32-38 \%$ of all marine species ${ }^{38}$. Yet almost nothing is known about how this biodiversity will respond to ocean acidification, warming, or the combination of both factors. To determine how algal, microbial, and non-coral invertebrate composition varied within each treatment, at the end of the experiment we 1) retrieved 3-tiered settlement tile arrays (modified Autonomous Reef Monitoring Structures ${ }^{39}$ ) which had recruited diverse benthic assemblages while soaking in the mesocosms for the duration of the experiment; 2) sampled the coral-associated algal endosymbionts and coral-associated microbes, as well as the water column-associated microbes; and 3) sampled the mesocosms for benthic, fleshy algae. The settlement tile arrays mimicked the threedimensional structure of the reef framework and provided a standardized tool with which to examine this often-overlooked cryptobenthic community. The settlement tiles provided four data sets: 1) benthic cover by functional group from tile image analysis; 2) sponge species richness from individual morphological identification with DNA barcoding confirmation; 3) coralline algal richness from individual morphological 
identification; and 4) overall metazoan richness from DNA metabarcoding of the homogenized biomass scraped from each tile array ${ }^{39-41}$. Given the relatively short reproductive cycles of many algae and invertebrate species (weeks to months), they experienced multiple generations over the course of the experiment, providing a time-integrated measure of the treatment effects on community composition and abundances. Throughout the course of the experiment the benthic community transitioned from early colonizing species to a mature and diverse community that underwent seasonal variation in abundance similar to adjacent reef communities (JV, KDB, MAT, CPJ, and RJT, pers. obs.)

Benthic cover analyses revealed that only a subset of the functional groups responded significantly to the treatments. Calcifying vermetid gastropods declined under acidification but increased under warming (Fig. 4, Table S3). Calcifying coralline algal cover increased with warming, non-calcifying turf algal cover decreased with warming, but neither group responded to acidification (Fig. 4, Table S3). Encrusting green algal cover increased in the combined future ocean scenario relative to the other treatments (Fig. 4, Table S2). Other calcifying taxa (including bivalves and serpulid worms) were unaffected by either low $\mathrm{pH}$ or elevated temperature (Fig. 4, Table S2,\& S3). The lack of an acidification effect on the benthic cover of most calcifying taxa is unexpected considering that individual species are often particularly sensitive to reduced $\mathrm{pH}$ in other studies ${ }^{9}$. Overall benthic community structure, however, was unaffected by $\mathrm{pH}$, indicating that it is not changes in the dominance of functional groups, but rather the relative sensitivity of species within functional groups that alter this structure. Benthic functional group community structure differed only by temperature, and this effect was driven largely by separation of the control and ocean warming treatments in a community ordination (Fig. 5, Table S4).

Species richness of coralline algae and most other heavily calcified taxa were not significantly different among treatments ${ }^{41}$, whereas the richness of some non-calcifiers declined under acidification (Table S3). Total metazoan richness on the settlement tiles was significantly reduced by acidification, significantly enhanced by warming, and these two factors offset each other in combination, resulting in species richness estimates that were not significantly different between the control and the combined future ocean scenarios ${ }^{41}$. The water column-associated microbial species composition and richness in the mesocosms did not differ significantly among treatments (Table S4). In contrast, the coral-associated microbial communities showed higher richness under warming and shifted structure depending on both temperature and pH (Table S3 \& S4). Richness of coral-associated algal symbionts (Symbiodinaceae, resolved to the genera Cladocopium and Durusdinium) increased under warming (ocean warming and combined future ocean treatments) because a higher proportion of the Montipora corals that survived those treatments hosted both symbiont genera rather than Cladocopium alone (Table S1). The proportional contribution of each type to the overall symbiont community, however, was unchanged by any of the treatments (Table S1). Likewise, fleshy algal species richness did not respond to either warming or acidification (Table S3). Hence, taxonomic and functional groups showed variable responses to the experimental treatments (Fig. 4). However, when all taxonomic datasets (sponges, coralline algae, and metabarcoding of metazoans from settlement tiles, coral-associated microbes, water columnassociated microbes, coral-associated algal endosymbionts, fleshy algae, and corals) were pooled to 
examine the effects of low $\mathrm{pH}$ and elevated temperature on proportional changes in overall species richness, the number of species was not significantly affected by any of the treatments (Fig. 5, Table S1).

Our experiments support predictions that future reefs will have less coral and reduced calcification rates. Yet, when experimental mesocosms were exposed to future ocean levels of simultaneous acidification and warming, consistent with current commitments under the Paris Climate Agreement (but in the absence of local stressors), we did not observe coral extirpation, reef community collapse, or net community carbonate dissolution. Instead, responses to ocean acidification, warming, and the combined future ocean stressors varied greatly among taxa, and many showed no significant effect of the treatments. Despite repeated severe annual heat stress (24 DHW annually), overall species richness was unchanged in future ocean conditions relative to present-day. The species richness or benthic cover of calcifiers (such as coralline algae) that have been predicted to do poorly based on previous work instead showed unexpected persistence, while some non-calcifiers (such as turf algae) declined under low pH or elevated temperature. Our results highlight the challenges of scaling up single-species studies to predict the outcome in diverse reef communities. Higher levels of acidification and warming, either due to unmitigated $\mathrm{CO}_{2}$ emissions or during periodic marine heatwaves, will undoubtedly result in more severe effects on reef ecosystems and reduced capacity to provide valuable ecosystem services.

The results of our long-term experimental study, which includes the most diverse spectrum of organismal and community responses examined to date, demonstrate that future ocean acidification and warming pose grave threats to coral reef ecosystems, and that unmitigated $\mathrm{CO}_{2}$ emissions will undoubtedly result in severe damage to these iconic ecosystems. However, these results also suggest that future reefs are likely to maintain a degree of function and avoid global collapse under realistic levels of ocean acidification and warming so long as local stressors can be mitigated ${ }^{42}$. Our study predicts that the community structure of reefs under future ocean warming will shuffle significantly, undoubtedly altering ecosystem function, but the ultimate outcome of such changes depends on species interactions and the specific ecological functions affected. Previous studies have underscored the importance of also mitigating local stressors for maintaining reef resilience $17,43,44$, especially because such local stressors increase the magnitude of coral loss from marine heatwaves ${ }^{42}$. The reef communities in these mesocosms were free from local anthropogenic stressors such as destructive fishing practices, sedimentation, and coastal pollution, which may have facilitated their persistence in the face of future ocean conditions. Overall, our results support projections that scleractinian corals will have lower abundance on future reefs, but also suggest that they will not be extirpated, that reef calcification will decline, yet will remain positive, and that a substantial fraction of reef biodiversity and ecosystem function could be preserved, even in the face of climate change, if serious action is taken to limit local human stressors on these iconic ecosystems.

\section{Declarations}

Acknowledgments: 
Thanks to A Arribas, L Bailey, B Bowen, M Burris, M Delano, S Dixon, K Giesy, M Hagedorn, M Hixon, M Kawachi, P Jokiel, S Lannon, M Lewis, M Locatis, J Melchiorre, M Moran, C Mortemore, B Nainiger, Y Noggle, E O'Flynn, M Otto, D Powell, H Rhine, K Rockwell, K Rodgers, K Ryan, K Snyder, S Solomon, W Tobias, J Walters, and A Wertz.

\section{Funding:}

Hawai邓i Sea Grant Omnibus 2014-2016, Project ID\#2180, the National Oceanographic and Atmospheric Administration's Ocean Acidification Program (CPJ, RJT).

NOAA OAP (MAT, CPJ, RJT, REB).

Herbert W Hoover Foundation (AGG),

Coordenação de Aperfeiçoamento de Pessoal de Nível Superior - Brasil (CAPES) fellowship and Clear Reef funds (MRdS),

National Science Foundation OA \#1416889, 1514861 (CPJ, RJT), \#1459536, 1838667, 1514859 (AGG), \#1612307 (JV).

Author contributions: The overall experiment was conceived and designed by CPJ and RJT. Funding was acquired by CPJ and RJT (SG award \#2180, NOAA OAP, and NSF OA award \#1416889, 1514861), MAT (NOAA OAP),AGG (NSF award \#1459536, 1838667, 1514859 and Herbert W. Hoover Foundation), and JV (NSF award \#1612307). Data collection and analyses were conducted as follows. Environmental monitoring: CPJ with assistance from KDB, EWB, LS, and TT. Coral calcification, bleaching, and survivorship, as well as rubble calcification: CPJ. Mesocosm calcification: CPJ with assistance from KDB, EWB, and LS. Coral colony genotyping: AC and RJT. Zooplankton: AGG and JTP. Coral color and physiology: RHM with assistance from JTP, KLD and AGG. Coral-associated microbes: JTP with assistance from RHM, KLD, and AGG. Settlement tile benthic cover: KDB, ATG, and CPJ with assistance from JV and MAT. Sponge richness: JV and MKW, with assistance from CPJ, KDB, ATG, MAT and RJT. Coralline algae richness: CAS with assistance from CPJ and CMS. Settlement tile metabarcoding: MAT, with assistance from JV, MKW, KDB, ATG, CPJ and RJT. Coral-associated algal symbionts: MRdS with assistance from CPJ and RJT. Water column-associated microbes: WS with assistance from CEN. Fleshy algae: NHY with assistance from CPJ and CMS. The first draft of the paper was written by CPJ. All authors contributed to discussion, data interpretation, manuscript revisions, and all approve the final manuscript.

Competing interests: Authors declare that they have no competing interests.

Data and materials availability: These data will be submitted to an online repository to enable open access with a persistent link and DOI. For the purpose of review, the datasets generated and analyzed herein are available from the corresponding author upon request. 


\section{References}

1. Hoegh-Guldberg, O. et al. Coral Reefs Under Rapid Climate Change and Ocean Acidification. Science 318, 1737-1742 (2007).

2. Pandolfi, J. M., Connolly, S. R., Marshall, D. J. \& Cohen, A. L. Projecting coral reef futures under global warming and ocean acidification. Science 333, 418-422 (2011).

3. Frieler, K. et al. Limiting global warming to $2{ }^{\circ} \mathrm{C}$ is unlikely to save most coral reefs. Nat. Clim. Change 3, 165-170 (2013).

4. Silverman, J., Lazar, B., Cao, L., Caldeira, K. \& Erez, J. Coral reefs may start dissolving when atmospheric CO2 doubles. Geophys. Res. Lett. 36, (2009).

5. Descombes, P. et al. Forecasted coral reef decline in marine biodiversity hotspots under climate change. Glob. Change Biol. 21, 2479-2487 (2015).

6. Eyre, B. D. et al. Coral reefs will transition to net dissolving before end of century. Science 359, 908-911 (2018).

7. Hoeke, R. K., Jokiel, P. L., Buddemeier, R. W. \& Brainard, R. E. Projected Changes to Growth and Mortality of Hawaiian Corals over the Next 100 Years. PLOS ONE 6, e18038 (2011).

8. Ainsworth, T. D. et al. Climate change disables coral bleaching protection on the Great Barrier Reef. Science 352, 338-342 (2016).

9. Kroeker, K. J. et al. Impacts of ocean acidification on marine organisms: quantifying sensitivities and interaction with warming. Glob. Change Biol. 19, 1884-1896 (2013).

10. Kornder, N. A., Riegl, B. M. \& Figueiredo, J. Thresholds and drivers of coral calcification responses to climate change. Glob. Change Biol. 24, 5084-5095 (2018).

11. Hall-Spencer, J. M. et al. Volcanic carbon dioxide vents show ecosystem effects of ocean acidification. Nature 454, 96-99 (2008).

12. Fabricius, K. E. et al. Losers and winners in coral reefs acclimatized to elevated carbon dioxide concentrations. Nat. Clim. Change 1, 165-169 (2011).

13. Barkley, H. C. et al. Changes in coral reef communities across a natural gradient in seawater $\mathrm{pH}$. Sci. Adv. 1, e1500328 (2015).

14. Hughes, T. P. et al. Global warming and recurrent mass bleaching of corals. Nature 543, 373-377 (2017). 
15. Rodolfo-Metalpa, R. et al. Coral and mollusc resistance to ocean acidification adversely affected by warming. Nat. Clim. Change 1, 308-312 (2011).

16. Camp, E. F. et al. Reef-building corals thrive within hot-acidified and deoxygenated waters. Sci. Rep. 7, 2434 (2017).

17. Jury, C. P. \& Toonen, R. J. Adaptive responses and local stressor mitigation drive coral resilience in warmer, more acidic oceans. Proc. R. Soc. B Biol. Sci. 286, 20190614 (2019).

18. Jokiel, P. L. et al. Ocean acidification and calcifying reef organisms: a mesocosm investigation. Coral Reefs 27, 473-483 (2008).

19. Comeau, S. et al. Flow-driven micro-scale pH variability affects the physiology of corals and coralline algae under ocean acidification. Sci. Rep. 9, 12829 (2019).

20. Dove, S. G., Brown, K. T., Van Den Heuvel, A., Chai, A. \& Hoegh-Guldberg, O. Ocean warming and acidification uncouple calcification from calcifier biomass which accelerates coral reef decline. Commun. Earth Environ. 1, 1-9 (2020).

21. Dove, S. G. et al. Future reef decalcification under a business-as-usual CO2 emission scenario. Proc. Natl. Acad. Sci. 110, 15342-15347 (2013).

22. Carpenter, R. C., Lantz, C. A., Shaw, E. \& Edmunds, P. J. Responses of coral reef community metabolism in flumes to ocean acidification. Mar. Biol. 165, 66 (2018).

23. Comeau, S., Carpenter, R. C., Lantz, C. A. \& Edmunds, P. J. Ocean acidification accelerates dissolution of experimental coral reef communities. Biogeosciences 12, 365-372 (2015).

24. Rogelj, J. et al. Paris Agreement climate proposals need a boost to keep warming well below $2{ }^{\circ} \mathrm{C}$. Nature 534, 631-639 (2016).

25. Grottoli, A. G., Rodrigues, L. J. \& Palardy, J. E. Heterotrophic plasticity and resilience in bleached corals. Nature 440, 1186-1189 (2006).

26. Jury, C. P., Thomas, F. I. M., Atkinson, M. J. \& Toonen, R. J. Buffer Capacity, Ecosystem Feedbacks, and Seawater Chemistry under Global Change. Water 5, 1303-1325 (2013).

27. Bahr, K. D., Tran, T., Jury, C. P. \& Toonen, R. J. Abundance, size, and survival of recruits of the reef coral Pocillopora acuta under ocean warming and acidification. PLOS ONE 15, e0228168 (2020).

28. Coles, S. L. et al. Evidence of acclimatization or adaptation in Hawaiian corals to higher ocean temperatures. PeerJ 6, (2018).

29. Shamberger, K. E. F. et al. Calcification and organic production on a Hawaiian coral reef. Mar. Chem. 127, 64-75 (2011). 
30. Albright, R. et al. Carbon dioxide addition to coral reef waters suppresses net community calcification. Nature 555, 516-519 (2018).

31. Perry, C. T. et al. Loss of coral reef growth capacity to track future increases in sea level. Nature 558, 396-400 (2018).

32. Jury, C. P., Whitehead, R. F. \& Szmant, A. M. Effects of variations in carbonate chemistry on the calcification rates of Madracis auretenra (= Madracis mirabilis sensu Wells, 1973): bicarbonate concentrations best predict calcification rates. Glob. Change Biol. 16, 1632-1644 (2010).

33. Bahr, K. D., Jokiel, P. L. \& Rodgers, K. S. Seasonal and annual calcification rates of the Hawaiian reef coral, Montipora capitata, under present and future climate change scenarios. ICES J. Mar. Sci. 74, 1083-1091 (2017).

34. Schoepf, V. et al. Coral Energy Reserves and Calcification in a High-CO2 World at Two Temperatures. PLOS ONE 8, e75049 (2013).

35. Jury, C. P., Delano, M. N. \& Toonen, R. J. High heritability of coral calcification rates and evolutionary potential under ocean acidification. Sci. Rep. 9, 20419 (2019).

36. Langdon, C. et al. Effect of calcium carbonate saturation state on the calcification rate of an experimental coral reef. Glob. Biogeochem. Cycles 14, 639-654 (2000).

37. Orte, M. R. de et al. Unexpected role of communities colonizing dead coral substrate in the calcification of coral reefs. Limnol. Oceanogr. 66, 1793-1803 (2021).

38. Fisher, R. et al. Species Richness on Coral Reefs and the Pursuit of Convergent Global Estimates. Curr. Biol. 25, 500-505 (2015).

39. Leray, M. \& Knowlton, N. DNA barcoding and metabarcoding of standardized samples reveal patterns of marine benthic diversity. Proc. Natl. Acad. Sci. 112, 2076-2081 (2015).

40. Ransome, E. et al. The importance of standardization for biodiversity comparisons: A case study using autonomous reef monitoring structures (ARMS) and metabarcoding to measure cryptic diversity on Mo'orea coral reefs, French Polynesia. PLOS ONE 12, e0175066 (2017).

41. Timmers, M. A. et al. Biodiversity of coral reef cryptobiota shuffles but does not decline under the combined stressors of ocean warming and acidification. Proc. Natl. Acad. Sci. (In press).

42. Donovan, M. K. et al. Local conditions magnify coral loss after marine heatwaves. Science $\mathbf{3 7 2}$, 977-980 (2021).

43. Hughes, T. P. et al. Phase Shifts, Herbivory, and the Resilience of Coral Reefs to Climate Change. Curr. Biol. 17, 360-365 (2007). 
44. Kennedy, E. V. et al. Avoiding Coral Reef Functional Collapse Requires Local and Global Action. Curr. Biol. 23, 912-918 (2013).

45. Lough, J. M., Anderson, K. D. \& Hughes, T. P. Increasing thermal stress for tropical coral reefs: 1871-2017. Sci. Rep. 8, 6079 (2018).

46. Storlazzi, C. D., Cheriton, O. M., van Hooidonk, R., Zhao, Z. \& Brainard, R. Internal tides can provide thermal refugia that will buffer some coral reefs from future global warming. Sci. Rep. 10, 13435 (2020).

47. Chaidez, V., Dreano, D., Agusti, S., Duarte, C. M. \& Hoteit, I. Decadal trends in Red Sea maximum surface temperature. Sci. Rep. 7, 8144 (2017).

48. McLachlan, R. H., Price, J. T., Solomon, S. L. \& Grottoli, A. G. Thirty years of coral heat-stress experiments: a review of methods. Coral Reefs 39, 885-902 (2020).

49. Bathen, K. A descriptive study of the physical oceanography of Kane'ohe Bay. in (1968).

50. Guadayol, Ò., Silbiger, N. J., Donahue, M. J. \& Thomas, F. I. M. Patterns in Temporal Variability of Temperature, Oxygen and $\mathrm{pH}$ along an Environmental Gradient in a Coral Reef. PLOS ONE 9, e85213 (2014).

51. Dickson, A. G., Sabine, C. L. \& Christian, J. R. Guide to Best Practices for Ocean CO2 Measurements. https://repository.oceanbestpractices.org/handle/11329/249 (2007).

52. OCADS - Program Developed for $\mathrm{CO}_{2}$ System Calculations. https://www.ncei.noaa.gov/access/ocean-carbon-data-system/oceans/CO2SYS/co2rprt.html.

53. Riddle, D. Product Review: Maxi-Jet Pro Series Pumps. Reefs.com https://reefs.com/magazine/product-review-maxi-jet-pro-series-pumps/.

54. Gorospe, K. D. et al. Local Biomass Baselines and the Recovery Potential for Hawaiian Coral Reef Fish Communities. Front. Mar. Sci. 5, (2018).

55. Hamner, W. M., Jones, M. S., Carleton, J. H., Hauri, I. R. \& Williams, D. McB. Zooplankton, Planktivorous Fish, and Water Currents on a Windward Reef Face: Great Barrier Reef, Australia. Bull. Mar. Sci. 42, 459-479 (1988).

56. Clark, T. D. et al. Ocean acidification does not impair the behaviour of coral reef fishes. Nature 577, 370-375 (2020).

57. Rodgers, K. S., Jokiel, P. L., Brown, E. K., Hau, S. \& Sparks, R. Over a Decade of Change in Spatial and Temporal Dynamics of Hawaiian Coral Reef Communities1. Pac. Sci. 69, 1-13 (2015). 
58. Franklin, E. C., Jokiel, P. L. \& Donahue, M. J. Predictive modeling of coral distribution and abundance in the Hawaiian Islands. Mar. Ecol. Prog. Ser. 481, 121-132 (2013).

59. Forsman, Z. H., Barshis, D. J., Hunter, C. L. \& Toonen, R. J. Shape-shifting corals: Molecular markers show morphology is evolutionarily plastic in Porites. BMC Evol. Biol. 9, 45 (2009).

60. Boulay, J. N., Hellberg, M. E., Cortés, J. \& Baums, I. B. Unrecognized coral species diversity masks differences in functional ecology. Proc. R. Soc. B Biol. Sci. 281, 20131580 (2014).

61. Veron, J. E. N., Stafford-Smith, M. G., Turak, E. \& DeVantier, L. M. Corals of the World,. (2016).

62. Stolarski, J. et al. The ancient evolutionary origins of Scleractinia revealed by azooxanthellate corals. BMC Evol. Biol. 11, 316 (2011).

63. Darling, E. S., Alvarez-Filip, L., Oliver, T. A., McClanahan, T. R. \& Côté, I. M. Evaluating life-history strategies of reef corals from species traits. Ecol. Lett. 15, 1378-1386 (2012).

64. NOAA Coral Reef Watch. NOAA Coral Reef Watch Version 3.1 Daily Global 5-km Satellite Coral Bleaching Degree Heating Week Product. (2018).

65. Cros, A., Toonen, R. J., Davies, S. W. \& Karl, S. A. Population genetic structure between Yap and Palau for the coral Acropora hyacinthus. PeerJ 4, e2330 (2016).

66. Cros, A., Toonen, R. J., Donahue, M. J. \& Karl, S. A. Connecting Palau's marine protected areas: a population genetic approach to conservation. Coral Reefs 36, 735-748 (2017).

67. Concepcion, G. T., Polato, N. R., Baums, I. B. \& Toonen, R. J. Development of microsatellite markers from four Hawaiian corals: Acropora cytherea, Fungia scutaria, Montipora capitata and Porites lobata. Conserv. Genet. Resour. 2, 11-15 (2010).

68. Faircloth, B. C. \& Glenn, T. C. Not All Sequence Tags Are Created Equal: Designing and Validating Sequence Identification Tags Robust to Indels. PLOS ONE 7, e42543 (2012).

69. Meirmans, P. GenoDive version 2.b14.

70. Selkoe, K. A. \& Toonen, R. J. Microsatellites for ecologists: a practical guide to using and evaluating microsatellite markers. Ecol. Lett. 9, 615-629 (2006).

71. Meirmans, P. G. \& Tienderen, P. H. V. genotype and genodive: two programs for the analysis of genetic diversity of asexual organisms. Mol. Ecol. Notes 4, 792-794 (2004).

72. Polato, N. R., Concepcion, G. T., Toonen, R. J. \& Baums, I. B. Isolation by distance across the Hawaiian Archipelago in the reef-building coral Porites lobata. Mol. Ecol. 19, 4661-4677 (2010). 
73. Gorospe, K. D. \& Karl, S. A. Genetic relatedness does not retain spatial pattern across multiple spatial scales: dispersal and colonization in the coral, Pocillopora damicornis. Mol. Ecol. 22, 3721-3736 (2013).

74. Gorospe, K. D., Donahue, M. J. \& Karl, S. A. The importance of sampling design: spatial patterns and clonality in estimating the genetic diversity of coral reefs. Mar. Biol. 162, 917-928 (2015).

75. Bates, D., Mächler, M., Bolker, B. \& Walker, S. Fitting Linear Mixed-Effects Models Using Ime4. J. Stat. Softw. 67, 1-48 (2015).

76. Lenth, R. V. Least-Squares Means: The R Package Ismeans. J. Stat. Softw. 69, 1-33 (2016).

77. R Core Team. R: A language and environment for statistical computing. (2018).

78. Nakajima, R. et al. Planktonic trophic structure in a coral reef ecosystem - Grazing versus microbial food webs and the production of mesozooplankton. Prog. Oceanogr. 156, 104-120 (2017).

79. Jokiel, P. L., Maragos, J. E., Franzisket, L., Stoddart, D. R. \& Johannes, R. E. Coral reefs: research methods. Coral growth: buoyant weight technique. UNESCO Paris 529-541 (1978).

80. Schneider, C. A., Rasband, W. S. \& Eliceiri, K. W. NIH Image to ImageJ: 25 years of image analysis. Nat. Methods 9, 671-675 (2012).

81. Andersson, A. J. et al. Net Loss of $\mathrm{CaCO} 3$ from a subtropical calcifying community due to seawater acidification: Mesocosm-scale experimental evidence. Biogeosciences vol. 613 (2009).

82. Chow, M. H., Tsang, R. H. L., Lam, E. K. Y. \& Ang, P. Quantifying the degree of coral bleaching using digital photographic technique. J. Exp. Mar. Biol. Ecol. 479, 60-68 (2016).

83. Rodrigues, L. J. \& Grottoli, A. G. Energy reserves and metabolism as indicators of coral recovery from bleaching. Limnol. Oceanogr. 52, 1874-1882 (2007).

84. Levas, S. et al. Organic carbon fluxes mediated by corals at elevated pCO2 and temperature. Mar. Ecol. Prog. Ser. 519, 153-164 (2015).

85. Baumann, J., Grottoli, A. G., Hughes, A. D. \& Matsui, Y. Photoautotrophic and heterotrophic carbon in bleached and non-bleached coral lipid acquisition and storage. J. Exp. Mar. Biol. Ecol. 461, 469-478 (2014).

86. Mclachlan, R. Extraction of Total Soluble Lipid from Ground Coral Samples. (2020) doi:10.17504/protocols.io.bc4qiyvw.

87. Bradford, M. M. A rapid and sensitive method for the quantitation of microgram quantities of protein utilizing the principle of protein-dye binding. Anal. Biochem. 72, 248-254 (1976). 
88. Mclachlan, R. Microplate Assay for Quantification of Soluble Protein in Ground Coral Samples. (2020) doi:10.17504/protocols.io.bdc8i2zw.

89. Cunning, R. \& Baker, A. C. Excess algal symbionts increase the susceptibility of reef corals to bleaching. Nat. Clim. Change 3, 259-262 (2013).

90. Apprill, A. M. \& Gates, R. D. Recognizing diversity in coral symbiotic dinoflagellate communities. Mol. Ecol. 16, 1127-1134 (2007).

91. Pochon, X. et al. Comparison of Endosymbiotic and Free-Living Symbiodinium (dinophyceae) Diversity in a Hawaiian Reef Environment1. J. Phycol. 46, 53-65 (2010).

92. LaJeunesse, T. C. \& Thornhill, D. J. Improved Resolution of Reef-Coral Endosymbiont (Symbiodinium) Species Diversity, Ecology, and Evolution through psbA Non-Coding Region Genotyping. PLOS ONE 6, e29013 (2011).

93. LaJeunesse, T. C. et al. High diversity and host specificity observed among symbiotic dinoflagellates in reef coral communities from Hawaii. Coral Reefs 23, 596-603 (2004).

94. Okansen, J. et al. vegan: Community ecology package. R package version 2.5. 4. 2019. (2019).

95. Cáceres, M. D. \& Legendre, P. Associations between species and groups of sites: indices and statistical inference. Ecology 90, 3566-3574 (2009).

96. Timmers, M. A., Vicente, J., Webb, M., Jury, C. P. \& Toonen, R. J. Sponging up diversity: Evaluating metabarcoding performance for a taxonomically challenging phylum within a complex cryptobenthic community. Environ. DNA n/a,

97. Vicente, J. et al. Unveiling hidden sponge biodiversity within the Hawaiian reef cryptofauna. Coral Reefs (2021) doi:10.1007/s00338-021-02109-7.

98. Folmer, O., Black, M., Hoeh, W., Lutz, R. \& Vrijenhoek, R. DNA primers for amplification of mitochondrial cytochrome c oxidase subunit I from diverse metazoan invertebrates. Mol. Mar. Biol. Biotechnol. 3, 294-299 (1994).

99. Chuang, L.-Y., Cheng, Y.-H. \& Yang, C.-H. Specific primer design for the polymerase chain reaction. Biotechnol. Lett. 35, 1541-1549 (2013).

100. Geller, J., Meyer, C., Parker, M. \& Hawk, H. Redesign of PCR primers for mitochondrial cytochrome c oxidase subunit I for marine invertebrates and application in all-taxa biotic surveys. Mol. Ecol. Resour. 13, 851-861 (2013).

101. Leray, M. et al. A new versatile primer set targeting a short fragment of the mitochondrial COI region for metabarcoding metazoan diversity: application for characterizing coral reef fish gut contents. 
Front. Zool. 10, 34 (2013).

102. Medina, M., Collins, A. G., Silberman, J. D. \& Sogin, M. L. Evaluating hypotheses of basal animal phylogeny using complete sequences of large and small subunit rRNA. Proc. Natl. Acad. Sci. 98, 97079712 (2001).

103. Chombard, C., Boury-Esnault, N. \& Tillier, S. Reassessment of Homology of Morphological Characters in Tetractinellid Sponges Based on Molecular Data. Syst. Biol. 47, 351-366 (1998).

104. Kearse, M. et al. Geneious Basic: An integrated and extendable desktop software platform for the organization and analysis of sequence data. Bioinformatics 28, 1647-1649 (2012).

105. Altschul, S. F., Gish, W., Miller, W., Myers, E. W. \& Lipman, D. J. Basic local alignment search tool. J. Mol. Biol. 215, 403-410 (1990).

106. Basset, Y., Novotny, V., Miller, S. E. \& Pyle, R. Quantifying Biodiversity: Experience with Parataxonomists and Digital Photography in Papua New Guinea and Guyana. BioScience 50, 899-908 (2000).

107. Oliver, I. \& Beattie, A. J. A Possible Method for the Rapid Assessment of Biodiversity. Conserv. Biol. 7, 562-568 (1993).

108. Farr, T. J., Broom, J., Hart, D. R., Neill, K. \& Nelson, W. A. Common coralline algae of northern New Zealand: an identification guide. (2009).

109. Kaleb, S., Alongi, G. \& Falace, A. Coralline algae preparatuion for scanning electron microscope and optical microscopy. in Protocols for macroalgae research 411-428 (CRC Press, 2018).

110. Bokulich, N. A. et al. Quality-filtering vastly improves diversity estimates from Illumina amplicon sequencing. Nat. Methods 10, 57-59 (2013).

111. Elbrecht, V., Peinert, B. \& Leese, F. Sorting things out: Assessing effects of unequal specimen biomass on DNA metabarcoding. Ecol. Evol. 7, 6918-6926 (2017).

112. Bista, I. et al. Annual time-series analysis of aqueous eDNA reveals ecologically relevant dynamics of lake ecosystem biodiversity. Nat. Commun. 8, 14087 (2017).

113. Klindworth, A. et al. Evaluation of general $16 \mathrm{~S}$ ribosomal RNA gene PCR primers for classical and next-generation sequencing-based diversity studies. Nucleic Acids Res. 41, e1-e1 (2013).

114. Kozich, J. J., Westcott, S. L., Baxter, N. T., Highlander, S. K. \& Schloss, P. D. Development of a DualIndex Sequencing Strategy and Curation Pipeline for Analyzing Amplicon Sequence Data on the MiSeq Illumina Sequencing Platform. Appl. Environ. Microbiol. 79, 5112-5120 (2013). 
115. Schloss, P. D. et al. Introducing mothur: Open-Source, Platform-Independent, CommunitySupported Software for Describing and Comparing Microbial Communities. Appl. Environ. Microbiol. 75, 7537-7541 (2009).

116. Quast, C. et al. The SILVA ribosomal RNA gene database project: improved data processing and web-based tools. Nucleic Acids Res. 41, D590-D596 (2013).

117. Wang, J. T. L. et al. New Techniques for DNA Sequence Classification. J. Comput. Biol. 6, 209218 (1999).

118. Tsuda, R. T. \& Abbott, I. A. Collection, handling, preservation, and logistics. in Ecological Field Methods: Macroalgae. Handbook of Phycological Methods 67-68 (Cambridge University Press, 1985).

119. Abbott, I. A. Marine red algae of the Hawaiian Islands. (Bishiop Museum Press, 1999).

120. Abbott, I. A. \& Huisman, J. M. Marine green and brown algae of the Hawaiian Islands. (Bishiop Museum Press, 2004).

121. Guiry, M. D. \& Guiry, G. M. AlgaeBase. AlgaeBase (2008).

\section{Figures}


a

\section{b}
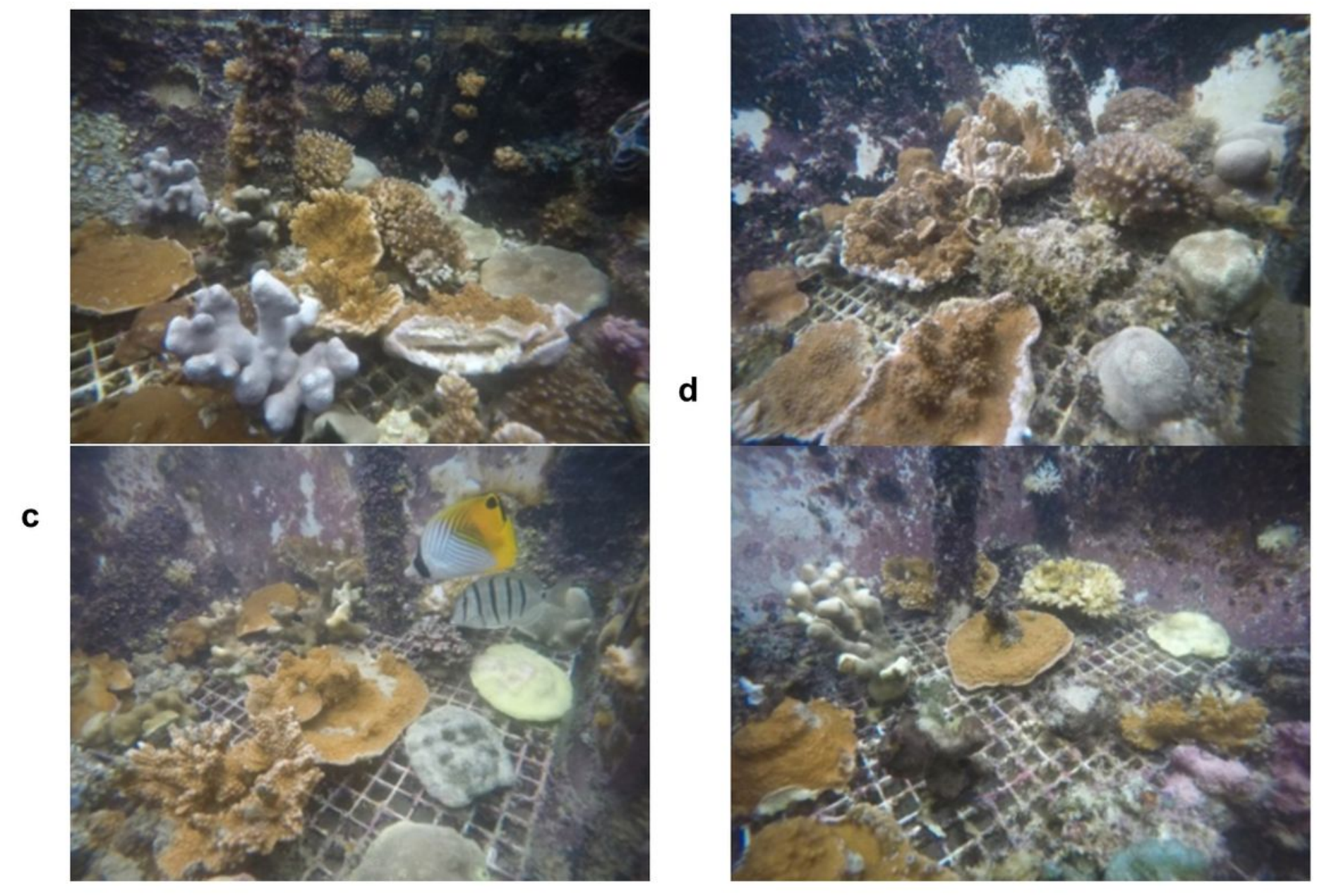

\section{Figure 1}

Representative photos of the mesocosms after nearly two years of exposure under treatment conditions. Images are from the (a) control, (b) ocean acidification, (c) ocean warming, and (d) combined future ocean treatments. 
a

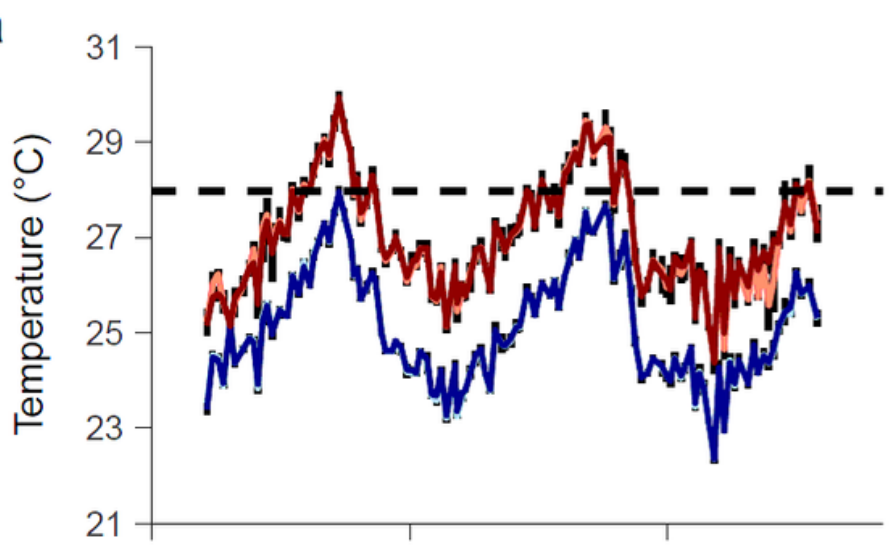

C

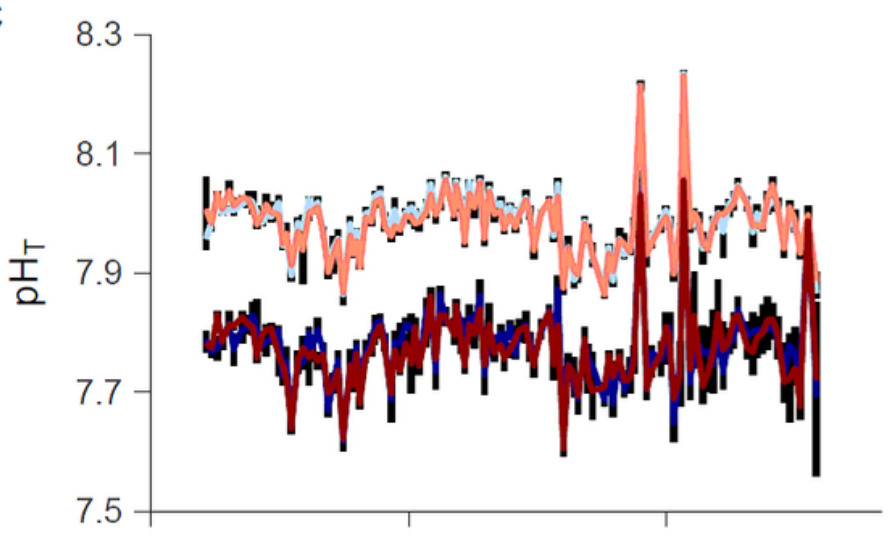

e

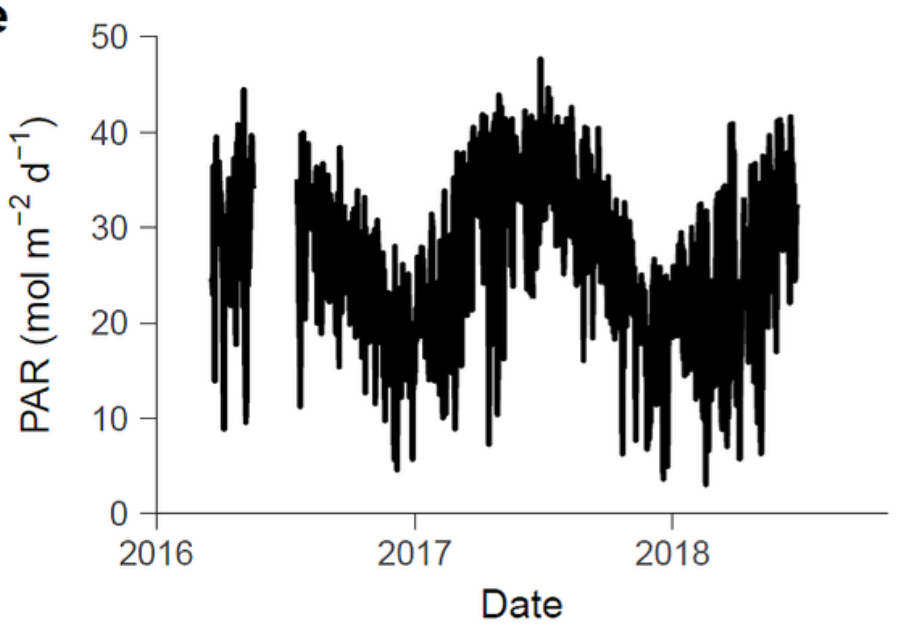

b

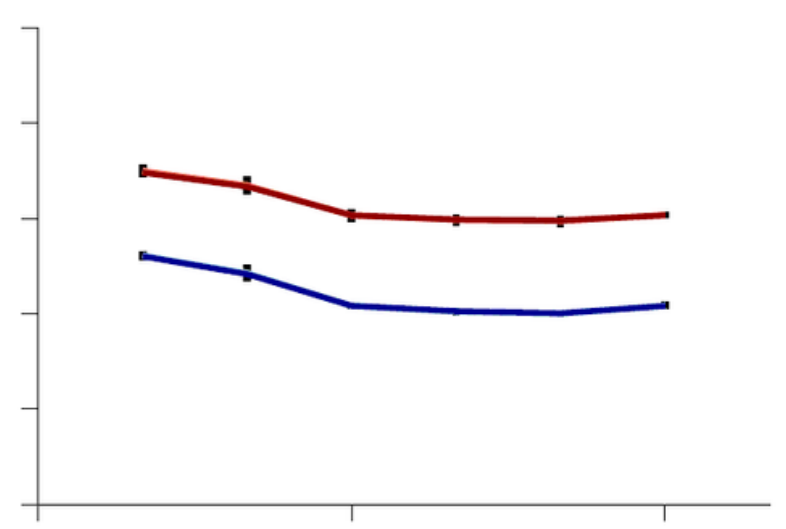

d
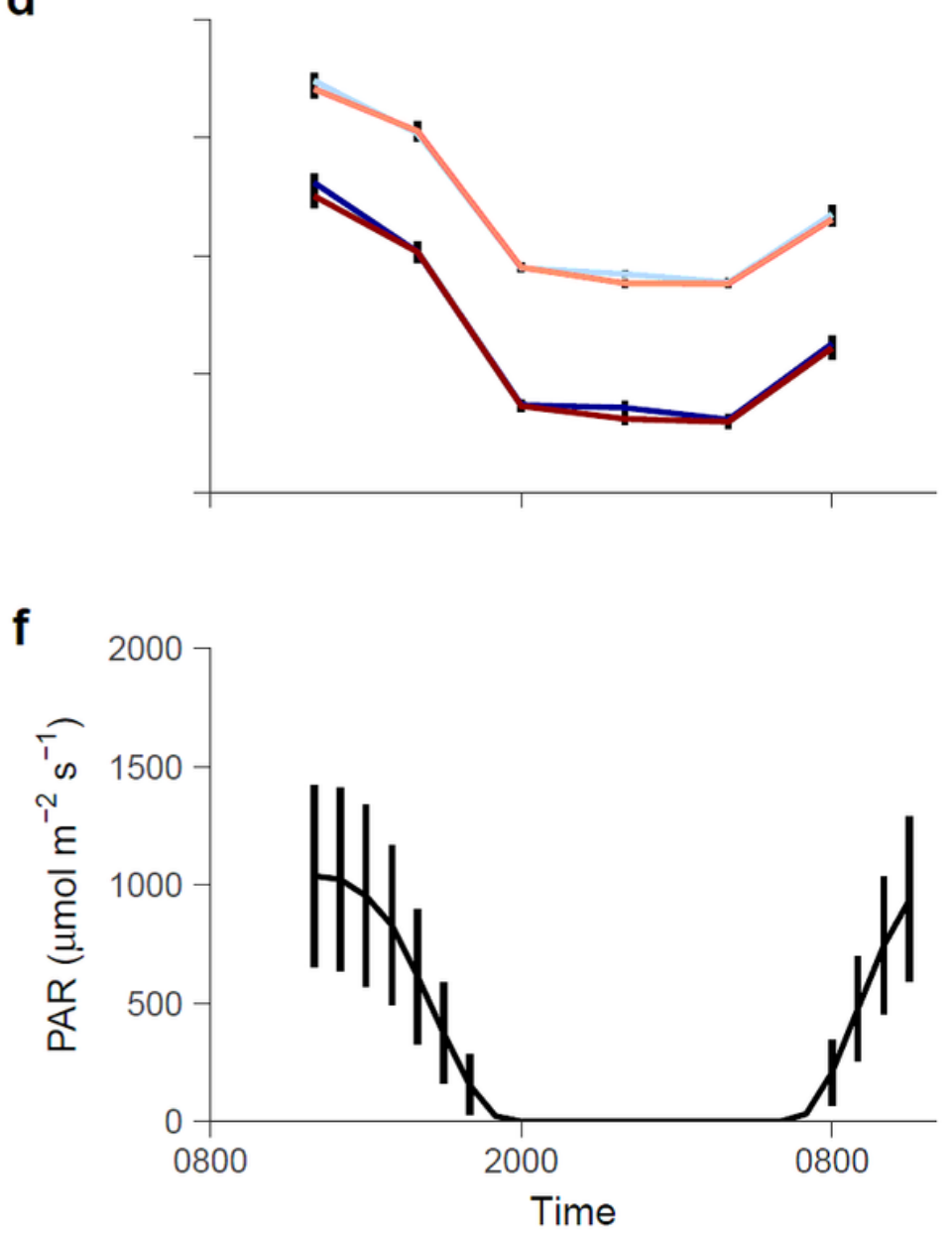

Figure 2

Environmental data from the mesocosm experiment. Panels show timeseries of temperature $(a, b)$ and $\mathrm{pH}$ (reported on the Total hydrogen ion scale) $(c, d)$, as well as photosynthetically active radiation (PAR) (e,f) as daily means over the course of the experiment $(a, c)$ and hourly means over the diel cycle $(b, d, f)$ for the control (light blue), ocean acidification (dark blue), ocean warming (light red), and combined future ocean (dark red) treatments (individual lines not visible where they overlap). Horizontal dashed line (a) shows the nominal coral bleaching threshold. Temperature and $\mathrm{pH}$ are derived from weekly samples collected at 
$1200 \mathrm{hr}$ local time as well as the mean of samples collected every $4 \mathrm{hr}$ over the diel cycle once per month. Irradiance data are daily integral values (e), or the mean of hourly values (f). All data (except e) shown as mean $\pm S D$. Error shown as vertical black bars (not visible where smaller than the line thickness).

Mesocosms were covered in $30 \%$ shade cloth to replicate irradiance at mean collection depth $(2 \mathrm{~m})$.

Maximum instantaneous irradiance was about $1730 \mu \mathrm{mol} \mathrm{m}-2 \mathrm{~s}-1$ in the mesocosms and $2470 \mu \mathrm{mol} \mathrm{m}-2$ $\mathrm{s}-1$ in the air. Water circulation in the mesocosms was provided by seawater pumps (10-15 cm s-1) and seawater turnover rate was $1 \mathrm{hr}$. See Table 1 and Fig. S1 for additional chemistry data, and see the Supplementary Information for additional details.
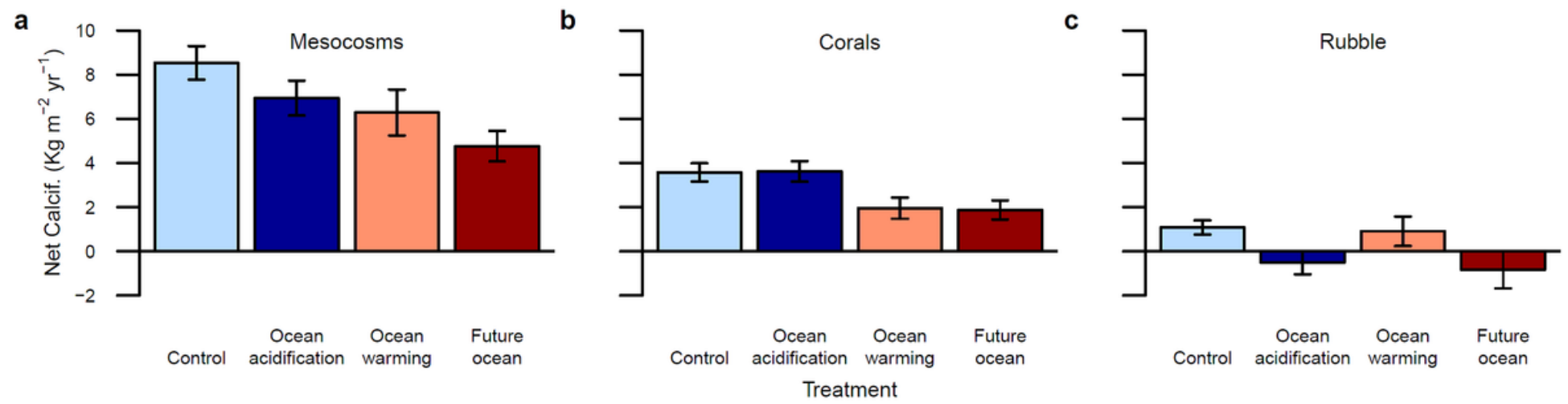

Figure 3

Effects of experimental acidification, warming, and combined future ocean conditions on net community calcification. (a) Entire mesocosm communities (sometimes referred to as net community calcification, NCC, or net ecosystem calcification, NEC, in other studies), (b) coral communities, and (c) rubbleassociated communities. Net calcification was determined by the total alkalinity anomaly technique in (a) and by the buoyant weight technique in $(b, c)$. Data bars show the mean $\pm S D(n=10$ communities per treatment). Mesocosm calcification declined with acidification and warming, whereas coral calcification declined only with warming and rubble calcification declined only with acidification. See Table S3 for test results.

a

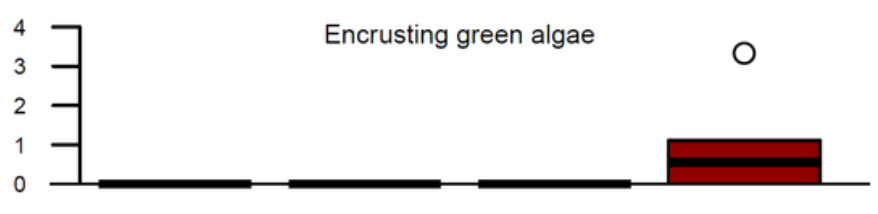

C

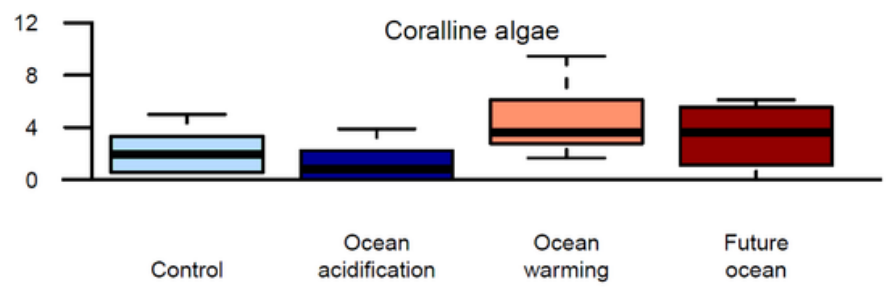

b

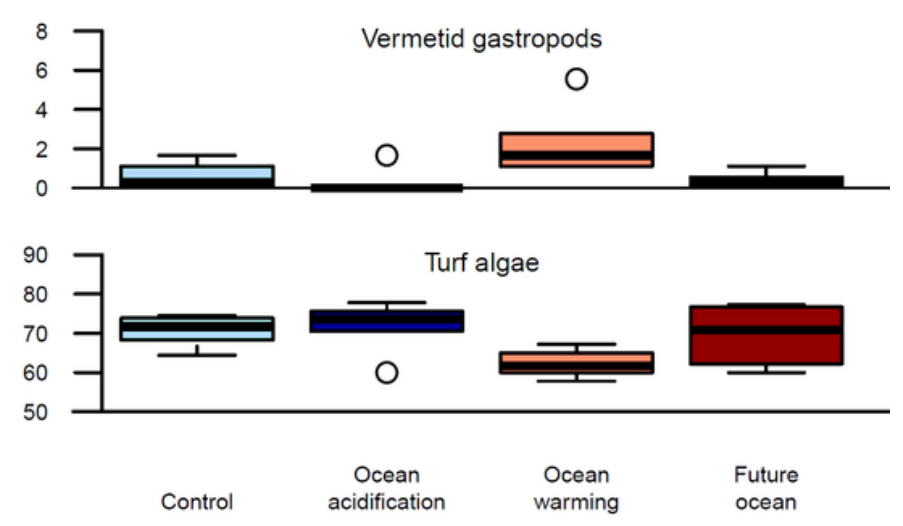

Figure 4

Benthic cover of functional groups on settlement tiles colonized in the mesocosms. (a), encrusting green algae, (b), vermetid gastropods, (c), coralline algae, (d), turf algae ( $n=6$ tile arrays per treatment). 
Vermetid gastropods, coralline algae, and turf algae showed significant responses to warming, whereas only vermetid gastropods responded negatively to acidification. Encrusting green algae attained significantly higher abundance under the combined future ocean scenario as compared to the other treatments. None of the other 10 functional groups responded significantly to treatment conditions. Boxplots show the median as center line, box limits are upper and lower quartiles, whiskers are 1.5x interquartile range, and open circles as outliers. Boxes are not visible where values were below detection limits of $0.09 \%$. See Table S2 \& S3 for test results.
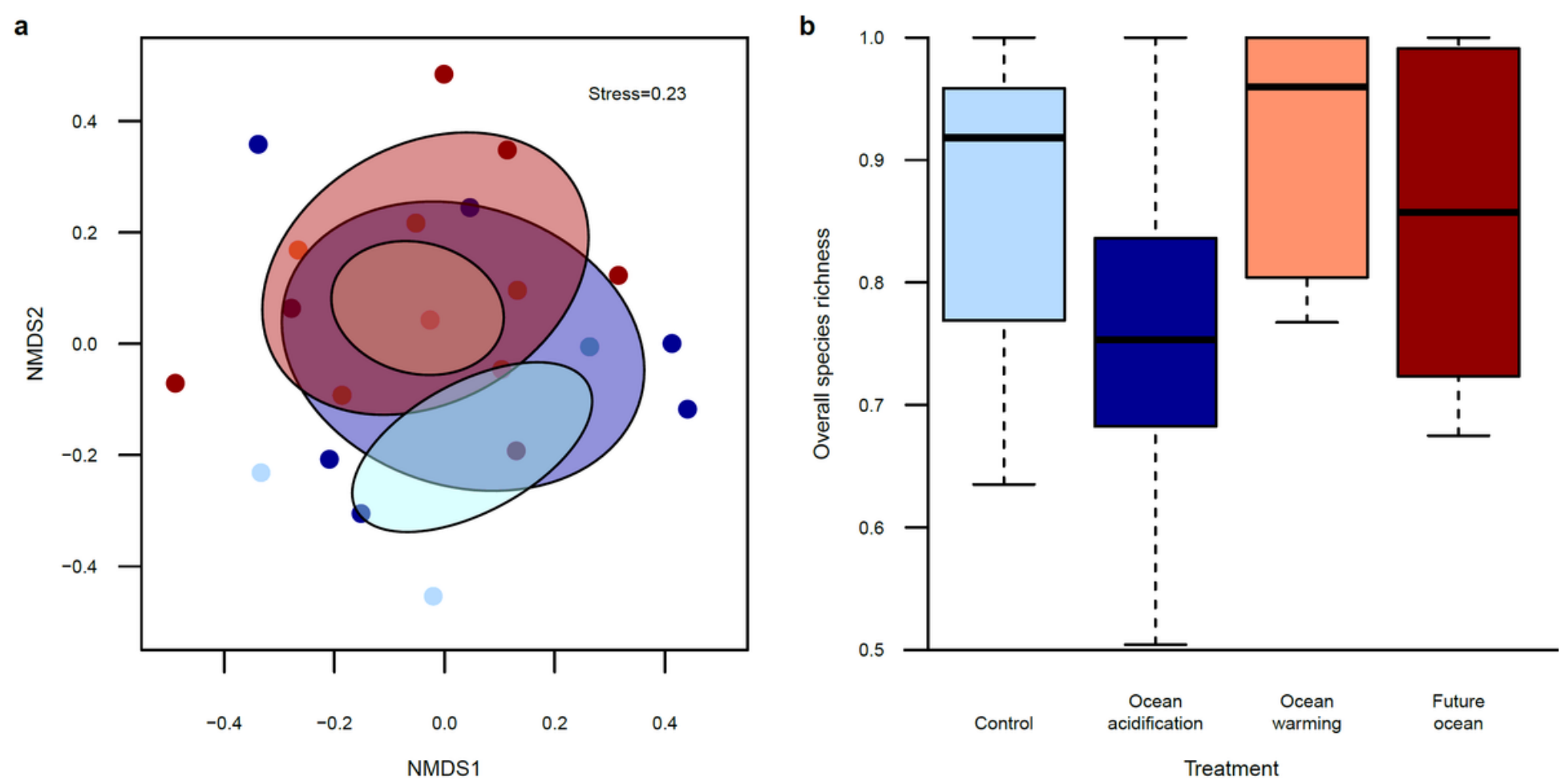

\section{Figure 5}

Benthic community structure and overall species richness in the mesocosms. (a) Non-metric multidimensional scaling ordination illustrating the effects of ocean acidification and warming on benthic community structure from settlement tiles colonized in the mesocosms for the control (light blue), ocean acidification (dark blue), ocean warming (light red), and combined future ocean treatments (dark red) ( $n=6$ tile arrays per treatment). Ellipses overlaid on scatterplots show the standard deviation around the centroid for each group. Community structure differed according to temperature but not $\mathrm{pH}$, which was driven largely by separation of the control and ocean warming treatments. (b) Treatment effects on overall species richness in the mesocosms (data shown as proportional variation in species richness relative to the maximum observed richness among treatments) derived from samples of sponges, coralline algae, and metabarcoding of metazoans from settlement tiles, coral-associated microbes, water column-associated microbes, coral-associated algal endosymbionts, fleshy algae, and corals $(n=8$ datasets representing thousands of species). Box-plots show the median as center line, box limits are upper and lower quartiles, whiskers are 1.5x interquartile range, and there were no outliers. Treatment effects were not significant. See Table S1, \& S4 for test results. 


\section{Supplementary Files}

This is a list of supplementary files associated with this preprint. Click to download.

- SupplementaryInformation.docx 